\title{
Fundamentals of Missionary Leadership: What We Know with Reasonable Confidence
}

\author{
Preprint for: \\ Evangelical Missions Quarterly \\ 2019, 55(4), 4-6
}

\author{
David R. Dunaetz ${ }^{1}$
}

\begin{abstract}
Missionaries find themselves in various leadership positions. The behavioral science literature on leadership can be confusing, but several principles can be asserted with reasonable confidence. Five of these principles are presented and applied to missionary contexts in order to help missionaries better contribute to completing the Great Commission.
\end{abstract}

Keywords
Missions, Missionary, Leadership, Missiology, Relationships, Accountability, Decision Making, Goals, Delegation

Missionaries often find themselves needing to provide leadership in one way or another in many of the organizations that they start or join, whether it be in a pioneer church plant, a missionary team, a mission organization, an association of national churches, or even perhaps a sending church. Sometimes these attempts at leadership go well, but other times, ... there are less than optimal results.

Because providing leadership in any field is so difficult, much research has focused on this topic, both from secular and Christian perspectives. But when studying leadership, it is often difficult to distinguish between opinions based on anecdotal evidence and trustworthy conclusions based on empirical evidence. Even in the academic literature, leadership theory is often fuzzy with little evidence to support some of its claims.

The Bible presents qualifications for church leaders (e.g., I Tim. 3, Titus 1) as well as some leadership principles concerning the importance of humility, serving others, and the dangers of dominating one's followers (e.g., Mt 20:2526, Mk 10:44-45, Jn 13:12-14). For several generations, the behavioral sciences have been studying specific aspects of leadership behavior that make leaders more or less effective. Several principles have emerged over the years that we know with relative certainty increase leadership effectiveness (Riggio, 2008). They are not applicable in every situation or in every culture, but they yield positive results in such a wide of range of situations and cultures that they are worth considering in whatever context we find ourselves.

1. Missionary leaders must focus on both the task and relationships.

Many, if not most, missionaries view their task as contributing to the achievement of the Great Commission, typically by making disciples, forming communities of Christ followers, or training others to contribute to fulfilling the Great Commission. More and more, missionaries also see social work as an element of their task. Since missionaries have a task, they need to focus on accomplishing it, even if they are not naturally goal-oriented.
Like all large tasks, accomplishing the Great Commission is dependent on a large number of smaller tasks, nested within each other. To accomplish the Great Commission, a church needs to be established in Town X. In order for a church to be established, there needs to be a children's program to teach the basics of the faith. In order to have such a program, teachers and assistants need to be trained. These are all important tasks, but they also all involve other people, all of whom have needs, feelings, hopes, and aspirations. Since love lies at the center of the gospel, missionaries tend to understand the importance of strong and healthy relationships.

In any leadership role, behaviors focused on accomplishing the tasks and developing relationships are both important (Yukl, Gordon, \& Taber, 2002). Suppose Ashley is a missionary in a young church and is responsible for developing the children's program. Research shows (Yukl, 2012) that her task-oriented behaviors (such as clarifying the goals of the programs, defining the processes used to achieve these goals, training church volunteers, monitoring the performance of volunteers, and solving problems as they arise) will have a number of positive effects: progress on achieving the goals of the children's program, understanding better how to achieve the goals in her specific context, better coordination of the church volunteers working toward the goals, and a more efficient use of the church's limited financial, material, and human resources. But research also shows that her relationshiporiented behaviors (such as eating with the volunteer staff, providing encouragement, asking for other people's opinions, recognizing others' contributions to the children's program, and expressing concern for others' families) will also create positive outcomes that lead to accomplishing the overall goals: volunteers will be happier with their work and role in the church, they will work better together as a team with fewer insurmountable conflicts, and the volunteers will have a stronger overall commitment to the church.

${ }^{1}$ Department of Leadership and Organizational Psychology, Azusa Pacific University, Azusa, California, USA ddunaetz@apu.edu 
2. The best missionary leaders will pay attention to their decision-making processes.

If missionary leaders want to make rational, high quality decisions, they must generate various options concerning a course of action to take and then thoroughly evaluate each option in order to choose the best (Greenberg \& Baron, 2003). They must also decide how they will generate and evaluate these options and how a final decision will be made. The process can range from completely autocratic (when the leader generates options, evaluates them, and decides without any input from those under his or her leadership) to completely participatory (where those under the leader generate options, evaluate them, and make a decision, perhaps with little or no input from the leader). In order to make the best decision, the one which will have the best results for the organization and its stakeholders, the missionary leader needs to determine the degree to which the process will be autocratic or participative (Vroom \& Yetton, 1973).

Suppose Zach is a missionary in a young church and is responsible for the church's evangelism program. He wants to plan an evangelistic event during the summer when everyone is on vacation. In order to choose the best type of event and how to carry it out, he has to decide to what degree he will make decisions and to what degree the church leaders will participate in the decision making progress. Factors that indicate that a more autocratic decision would be best include:

1. The need for a quick decision.

2. Zach's own expertise in planning evangelistic activities in the cultural context relative to the church leaders' expertise.

3. The willingness of the church leaders to unquestionably accept Zach's decision and implement it.

4. The degree to which church leaders have goals which are opposed to Zach's goals.

However, there may be factors that indicate that more participative decision-making would be best. These include:

1. The need for a high quality solution.

2. The need for a creative solution.

3. The expertise of the church leaders concerning evangelism in their cultural context.

4. The likelihood that an autocratic decision would create conflict.

5. The church leaders' reluctance to support and implement an autocratic decision.

Zach needs to weigh all these factors carefully before choosing how autocratic and how participative the decision making process will be. Although a missionary's goal may be to enable a young church to make all of its decisions by itself, oftentimes additional training is more appropriate than using a participative decision process when those involved lack either the expertise needed to make the best decisions or have interests that run counter to the gospel.

3. Effective missionary leaders set goals and monitor their achievement.

A good leader will monitor the performance of everyone in the group that he or she is leading, even if it can be a bit exhausting. People generally want their performance to improve, especially if they are working in a values-driven organization such as a church or a mission. However, if no one expresses an interest in the quality of their work, the quality may go down since it does not seem important to anyone. If they lack the knowledge and the techniques to carry out their responsibilities, the quality of their work will be lower than it should be. If they do not understand that the quality of their work could be better (i.e., they have a blind spot), it is unlikely to improve. For these reasons, missionary leaders need to provide feedback to the people whom they lead concerning the quality of their work.

This feedback needs to be both supportive and constructive in order to have positive consequences. Suppose Richard is the field leader for a group of missionaries working with a large unreached people group in an urban setting. Supportive interaction with the missionaries for whom he is responsible will demonstrate that he is concerned about the other missionaries' well-being and that he wants to see them succeed in all areas of life. This requires warmth, empathy, and desire to learn about and understand the reasons for less than optimal results. Richard's feedback should also be constructive. It should provide specific information on how to improve performance. For the feedback to be constructive, Richard must also be willing to change the evaluation of a missionary's work when he receives new, relevant information concerning the missionary's exact situation and circumstances.

One of the best ways leaders can help those whom they are leading to become more productive is by setting challenging, measurable goals and monitoring the progress made in achieving these goals (Dunaetz, 2013; Locke \& Latham, 2006). Suppose one of the missionaries that Richard supervises, Joshua, is responsible for a training program in a national network of churches. A goal such as presenting the training program to 20 different groups in the next two months can be useful for several reasons. It will help Joshua stay focused. He knows he needs to meet with 20 groups, so he is motivated to organize his time to reach this goal. The goal also provides information about the effectiveness of the approach he uses to accomplish it. If, after a month, he has been only able to schedule five group meetings by meeting individually with leaders, he will be motivated to creatively think of other ways to meet his goal of twenty group meetings. In general, having goals motivates hard work and creativity in missionaries by influencing the choice of how they will spend their time, the effort that they will spend on the task, and their persistence when they run into obstacles.

But not all goals increase productivity. For Joshua's goals to be effective, they must be in alignment with the overarching goals of his mission organization. They must also be specific and measurable; studies show that "do your best" goals usually lead to lower results than goals with a specific target. The goals must be challenging, yet realistic; they should help keep Joshua focused on the task so that he works to his full potential. Perhaps most importantly, especially in missionary contexts, they should focus on missionary behavior, not on the behavior of others. Achieving the goal should be within the control of the missionary, not something that depends primarily on what others or God chooses to do. Goals that set targets for conversions are especially dangerous. Goals must focus on specific tasks that missionaries can accomplish, such as 
sharing the gospel a certain number of times or organizing a certain number of meetings by a target date.

4. The most effective missionary leaders delegate appropriately and use delegation as a form of training.

Delegation in missionary contexts can be defined as a "power-sharing process" that occurs when a missionary gives the responsibility and power to a person to make decisions that were previously made by the missionary (Yukl, 2012, p. 87). Delegation is a common biblical theme, exemplified by Jethro encouraging Moses to delegate some legal decisions to capable leaders (Ex. 18:17-26) and Paul delegating to Titus the responsibility of appointing elders in Crete (Titus 1:5). Delegation involves not just giving people new responsibilities, but also the power or authority to make the necessary decisions as to how to carry out these responsibilities.

Delegating can be scary, especially when missionaries are trying to maintain the quality of an already shaky program or when they are having difficulty establishing their own identity and role in a culture. However there are excellent reasons to delegate, as well as reasons to not delegate (Yukl \& Fu, 1999)

\section{Reasons for Missionary Delegation}

When missionaries delegate to others, they have an opportunity to develop new skills in others who can use them more efficiently in the future. This often means that the missionary will have to invest additional time into training the people who receive new responsibilities and monitoring their progress, providing sufficient feedback to ensure their success.

Delegation to others enables some problems to be addressed more quickly by people better equipped to deal with them. Once again, this depends on the training that the person receiving the new responsibilities has received, as well as the context in which the problems arise.

Delegation can save missionaries time if they feel overloaded. Less important ministry-related tasks can be delegated to others who are able to do them, freeing the missionaries for more important projects. If this is not possible, training people for ministry should be a higher priority.

Yet at the same time, delegation can create more problems than it solves. Missionary leaders need to understand when to delegate and when not to delegate.

\section{Reasons Not to Delegate}

A missionary should not delegate a task to a person when that person does not have the quality relationships with stakeholders that are needed for successful completion of the task. In this case, the missionary leader needs to help those under him or her to develop the necessary network of quality relationships.

Missionaries should not delegate tasks which are too difficult for a person. The people whom a missionary is training are only likely to do a task well, or to at least learn from being delegated a task, if it is within their ability. Even if they have received training, people should not be given responsibilities that require abilities that they do not possess. Rather, people should be given tasks that are progressively more difficult until it becomes clear that the next level is likely to be too difficult.

\section{Successful missionary leaders are flexible and} willing to change.

The ability and willingness to adjust one's ministry in light of changes, either external or internal to the organization, is crucial for missionary leaders to lead people to where God wants them to be. If task-related behavior and relationshiprelated behavior are the two principle categories of what leaders do, change-related behavior is the third most common (Yukl, et al., 2002).

Some of the most important change-related behavior involves paying attention to changes in one's ministry context, both local and general cultural changes. Effective missionary leaders will analyze these changes, seeking to find and understand the threats and the opportunities that develop. They will modify existing structures and programs to protect from the threats and develop both new and existing ones to take advantage of the opportunities. For example, if some current event causes debate on a culture's view of sexual ethics, the missionary may provide a series of studies on sexual ethics from a Christian perspective. As for the structure of a program, the missionary will experiment to see what works, monitoring the results closely and will abandon attempts that do not lead to the desired outcomes. In addition to understanding the threats and opportunities that develop, missionary leaders need to continually communicate these to the people whom they lead, reframing the changes as an opportunity to see God work if they are willing to respond to them in faith (cf. Dunaetz, 2010).

Missionary leaders who are open to change will also study Christian leaders who are experiencing success in order to discover ideas that will help them achieve their own goals in a given context. These missionaries will ask difficult questions in order to determine if the successful ministry is effective because of the reasons given and to determine if the strategies used are likely to be effective in their own context. Change-oriented missionary leaders must also look for opportunities for change and growth that exist among the people whom they are leading. Missionary leaders need to understand people's strengths and seek to build upon them. It is especially important to recognize and develop emerging leaders, providing them with opportunities to maximize their spiritual growth and develop their skills. Feelings of jealousy, insecurity, or disdain for young, emerging leaders are often signs of misplaced priorities.

Being a missionary leader is not easy. Knowing and reflecting upon some of the key principles that are necessary to provide effective leadership can help, but the difficulties of specific situations often make putting these principles into practice very difficult. For this reason, dependence on the Lord through prayer and his Word is all the more important if missionary leaders wish to fulfill the ministry to which he has called them.

\section{References}

Dunaetz, D. R. (2010). Long distance managerial intervention in overseas conflicts: Helping missionaries reframe conflict along multiple dimensions. Missiology: An International Review, 38, 281-294. 
Dunaetz, D. R. (2013). Goals and accountability for ministry Author biography

effectiveness: Insights from psychological science. David R. Dunaetz is Assistant Professor of Leadership and Dharma Deepika: A South Asian Journal of Organizational Psychology at Azusa Pacific University. He Missiological Research, 17, 66-79.

was a church planter in France for 17 years with World-Venture

Greenberg, J., \& Baron, R. A. (2003). Behavior in where he planted two churches and helped a third move beyond organizations: Understanding and managing the missionary dependence human side of work (8th ed.). Upper Saddle River, NJ: Pearson.

Locke, E. A., \& Latham, G. P. (2006). New directions in goalsetting theory. Current Directions in Psychological Science, 15, 265-268.

Riggio, R. E. (2008). Introduction to industrial/organizational psychology (5th ed.). Upper Saddle River, NJ: Pearson.

Vroom, V. H., \& Yetton, P. W. (1973). Leadership and decision-making. Pittsburgh, PA: University of Pittsburgh Press.

Yukl, G. (2012). Leadership in organizations (8th ed.). Upper Saddle River, NJ: Prentice Hall.

Yukl, G., \& Fu, P. P. (1999). Determinants of delegation and consultation by managers. Journal of Organizational Behavior, 20, 219-232.

Yukl, G., Gordon, A., \& Taber, T. (2002). A hierarchical taxonomy of leadership behavior: Integrating a half century of behavior research. Journal of Leadership \& Organizational Studies, 9, 15-32. 


\section{Author biography}

David R. Dunaetz David R. Dunaetz is Assistant Professor of Leadership and Organizational Psychology at Azusa Pacific University. He was a church planter in France for 17 years with WorldVenture where he planted two churches and helped a third move beyond missionary dependence 